\title{
A PILOT-SCALE TECHNOLOGY OF COMPRESSED BIOGAS TREATMENT SYSTEM
}

\author{
M. M. Badr*
}

\section{ABSTRACT}

Biogas is one of the most important sources of a clean and environmentally friendly energy strongly emerged as a potential alternative fuel. It contains of 60-70\% methane, 30-40\% carbon dioxide, traces of hydrogen sulfide and fractions of water vapor. However, its wide extent use is obstructed by the related problems which represented in a low energy density due to the presence of many impurity and generation by low pressures as well as the means absence for compression and bottling. Some studies for production biogas and upgrading technologies have been performed in order to improve the gas yield and methane ratio without working on design of an integrated system for biogas processing. This study presents technology of integrated biogas treatment system in the form of a combined experimental scale. The performance of treatment system was experimentally estimated under four different discharge pressures (200, 400, 500 and $600 \mathrm{kPa}$ ) and gas flow rates $\left(2.0,2.4,2.8\right.$ and $\left.3.0 \mathrm{~m}^{3} . \mathrm{h}^{-1}\right)$. The experimental results reveal that the values of actual capacity and volumetric efficiency were $2.36 \mathrm{~m}^{3} \cdot \mathrm{h}^{-1}$ and $84.89 \%$. Furthermore, the highest of heating value per actual capacity and energy generation reached 72.10 MJ.h and $20.03 \mathrm{~kW}$.h respectively at pressure 600 $k P a$ and gas flow rate of $3 \mathrm{~m}^{3} \cdot h^{-1}$.

\section{INTRODUCTION}

T $\mathrm{n}$ recent times, the increases demand on heat and power due to advanced industrialization and economic development which has led to the higher pressure on traditional energy sources. This exploitation has been conforemed same serious environmental problems such as changing in climate. Therefore, alternative sources must be provided to keep sustainability and stability of the massive industrial development. The natural resources of renewable energy like solar, biomass, wind, hydropower and geothermal are environmentally friendly and sustainable in nature as well are available in all parts of the country during the year.

\footnotetext{
*Assistant professor of Agric. Eng., Fac. of Agric., Zagazig Univ. Egypt.
} 
Biogas technology is a clean low carbon technique which embodies efficient management of organic wastes and conversion into clean renewable biogas which can be used as an energy source in several applications to achieve sustainable development. Methane is an important renewable fuel, environmentally friendly, clean, versatile, and cheap that can be produced by enriching raw biogas that is commonly produced by anaerobic digestion of organic matter in the oxygen absence. Raw biogas consists mainly methane and carbon dioxide and small traces of the hydrogen sulfide, water vapor and nitrogen. Biogas treatment technology has obtained extreme attention result to rising natural gas and oil prices and increasing global demand for renewable fuel in many countries. Treatment technology for raw biogas after the production process creates new horizons towards sustainable energy management. The energy content of biogas is in direct proportion to the methane concentration and by removing carbon dioxide and unwanted substances such as hydrogen sulfide, water, nitrogen and particulates to enhance the quality of the raw biogas. The purification, compression and storage system has been designed to use the purified biogas for cooking applications in village households. Where biogas is purified, compressed and storage in cylinders which makes it simple to use. The purification process was done by using the limestone crystals to reduce the carbon dioxide percentage in raw biogas, the hydrogen sulfide was removed by a fiber container with steel wool and a container with silica gel was utilized to reduce the water vapor in the purified gas (Budzianowski et al., 2017).

Gas compressor selection is important procedure which play instrumental role in gas treatment system. Appropriate selection of treatment system and its sizing is worthy concern which will give proper compressor performance. Various criteria are taken into considerations while design of treatment unit to obtained on the desired efficiency including temperature, pressure, flow rate and power rating (Chaitanya et al., 2017). With regard to compression system, a lever compressor was used to compress the purified biogas of $400 \mathrm{kPa}$ in a storage tank of $0.5 \mathrm{~m}^{3}$ at operating time of 30 min, (Mohanty et al., 2016). The biogas treatment process consists of different steps such as biogas purification, compression and bottling. Using small-scale model, the purified biogas can be compressed and filled into 
small cylinder with a volume of $0.105 \mathrm{~m}^{3}$ and gas flow rate of $0.42 \mathrm{~m}^{3}$ per hour as a sustainable energy source of supply for heat and power, (Gaikwad and Katti 2015). The biogas utilization as an effective energy source relies highly on methane concentration. Thus, biogas treatment is essential procedure in order to have further energy content per volume of compressed gas and to remove the corrosive impact of hydrogen sulfide, where purified gas is ready for compression and storage into the cylinders, which is potential after removing carbon dioxide, water vapor and hydrogen sulfide. Raw biogas treatment increases the methane concentration in biogas with a view to have high calorific value as well as to remove the greenhouse gases effect. Biogas compression was executed up to pressure of 5 bar in total time of 12-14 min and storage inside normal cylinder by using a refrigerant compressor, (Nallamothu et al., 2013).

Hybrid multi-stage processes can be used in biogas treatment depending on the concentration and natural of impurities as well as on the treated gas characteristics and the selection of appropriate technology is dependent on a domestic conditions and requirements through end use purposes and systems. Pressure swing adsorption has low energy requirements and a low capital costs as well as an effective purification efficiency where typical value of methane purity is equal to 92\% (Ryckebosch et al., 2011). The heating value of biogas is proportional to the methane content, meaning

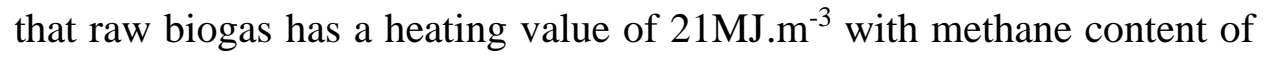
$50 \%$, while purified biogas of $100 \%$ methane content has heating value of 33.41 MJ.m ${ }^{-3}$ which makes purified biogas more convenient for use in higher value applications. Raw biogas contains unwanted contents and is produced under low pressure is not cannot be used it in this case, so it goes under purification process where any unwanted components is to be removed like carbon dioxide, hydrogen sulfide moisture hence get percentage of methane up to $90 \%$. The obtained gas is bottled in cylinders by a capacity from 75 to 200 liters under high pressure, increasing pressure leads to temperature increment which requires to decrease temperature by using a cooling unit, (Yadav et al., 2018).

Researches continue on biogas effort toward further improve the total efficiency and reduce operation and maintenance costs of energy management system. Most available information's were obtained from 
separated-stages process of biogas treatment in laboratory-scale trials. Therefore, further efforts are demanded for bridging the knowledge gap between these tests and pilot scale systems. Previous technologies for production and processing of raw biogas depend often on multistage processes and large-scale structure, which adds to the cost of biogas processing. Issue the design of an efficient technique for biogas treatment with compact experimental size in a manner that could be generalized as well as the system efficiency, operational condition, the environmental impact and cost implication of the selected technique all requires research and development.

In this context, the current paper presents a technology of compact biogas system, starting from purification of gas to the compression and bottling process in a safe and efficient manner to protect the ecosystem from the negative effects by improving quality.

\section{MATERIALS AND METHOD}

Experiments were carried out in a biogas laboratory at Department of Agricultural Engineering, Faculty of Agriculture, Zagazig University. Current study focusses to design compact treatment system to facilitate the multiple uses of the compressed biomethane gas (CBG). The implemented procedures in this work be embodied the multiple stages technique that including both biogas purification, compression and bottling system to use biomethane gas produced in several Industrial applications. Compression is done by reciprocating gas compressor at average pressure between 200 and $600 \mathrm{kPa}$ as well filling and storage of methane gas after purified of the raw biogas. In this upgrading process where carbon dioxide is separated from the raw biogas, some of the other undesirable compounds are also separated to prevent mechanical wear and corrosion of the upgrading system itself.

\section{Physical properties}

Methane is used in industrial processes and be transported in the gaseous state. It is used as a ovens fuel, homes, automobiles, water heaters and as a fuel for electricity generation. Methane gas is colorless, odorless and tasteless, the physical properties can be expressed by a molecular weight, critical temperature \& pressure, gas density and specific gravity. Values are given for gas phase at Normal Temperature and Pressure, NTP is defined as $20^{\circ} \mathrm{C}$ $(293.15 \mathrm{~K})$ and $101.325 \mathrm{kPa}$, as follows. 
Table: 1 Physical properties of the biomethane gas.

\begin{tabular}{|l|l|}
\hline Molecular weight, $\mathrm{g} \cdot \mathrm{mol}^{-1}$ & 16.04 \\
\hline Critical pressure, $\mathrm{kPa}$ & 45.99 \\
\hline Density, kg.m & \\
\hline Relative gas density & 0.657 \\
\hline Gas constant- $\mathrm{R}, \mathrm{kJ} \cdot \mathrm{kg}^{-1} \cdot{ }^{\circ} \mathrm{C}^{-1}$ & 0.700 \\
\hline Specific heat ratio, $\mathrm{n}$ & 0.5183 \\
\hline Specific Gas Constant, $\mathrm{kJ} \cdot \mathrm{kg}^{-1} \cdot{ }^{\circ} \mathrm{C}^{-1}$ & 1.306 \\
\hline
\end{tabular}

\section{Compact treatment system}

The main parts of the compressed biomethane gas system are purification unit, gas compressor, suction port, discharge port and storage unit. All these parts have been shown in figure 1 .

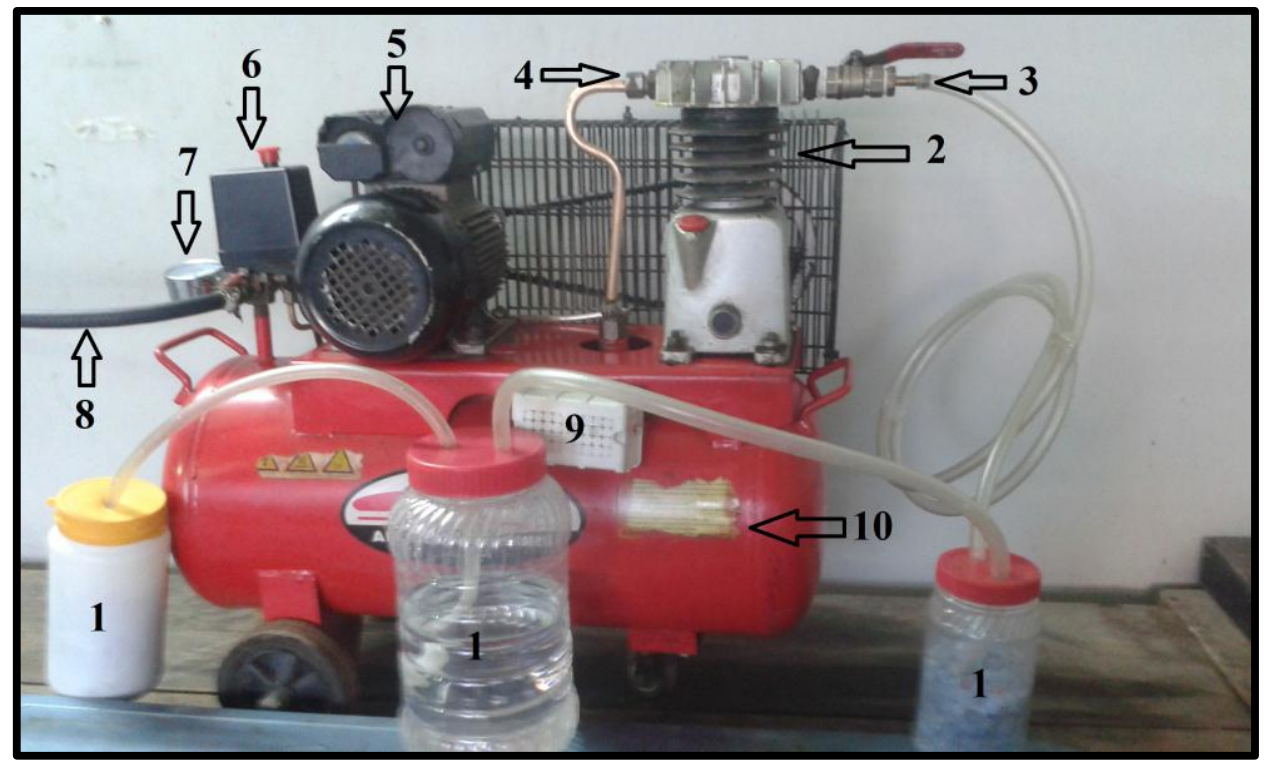

\begin{tabular}{|c|l|c|l|}
\hline No. & Part Name & No. & Part Name \\
\hline $\mathbf{1}$ & Purification Unit & $\mathbf{6}$ & Pressure Controller \\
\hline $\mathbf{2}$ & Gas Compressor & $\mathbf{7}$ & Pressure Gauge \\
\hline $\mathbf{3}$ & Suction Port, & $\mathbf{8}$ & Outlet Port \\
\hline $\mathbf{4}$ & Discharge Port & $\mathbf{9}$ & Main Switch \\
\hline $\mathbf{5}$ & Electric Motor & $\mathbf{1 0}$ & Storage Unit \\
\hline
\end{tabular}

Fig. 1: Illustrated view of a pilot-scale biogas treatment system.

Biogas was produced by using industrial digester. It is identified total solid amount and weight of influent required that is added to the digester with concentration of $8 \%$. Biogas treatment system is single stage compression in 
which gas is sucked in a chamber and compressed with the help of a reciprocating piston. The compression of the gas takes place in a single cylinder and deliver it to the storage tank after removing carbon dioxide, hydrogen sulfide and water vapor by using purification unit to increase the energy density of the methane gas.as shown in Figure 2.

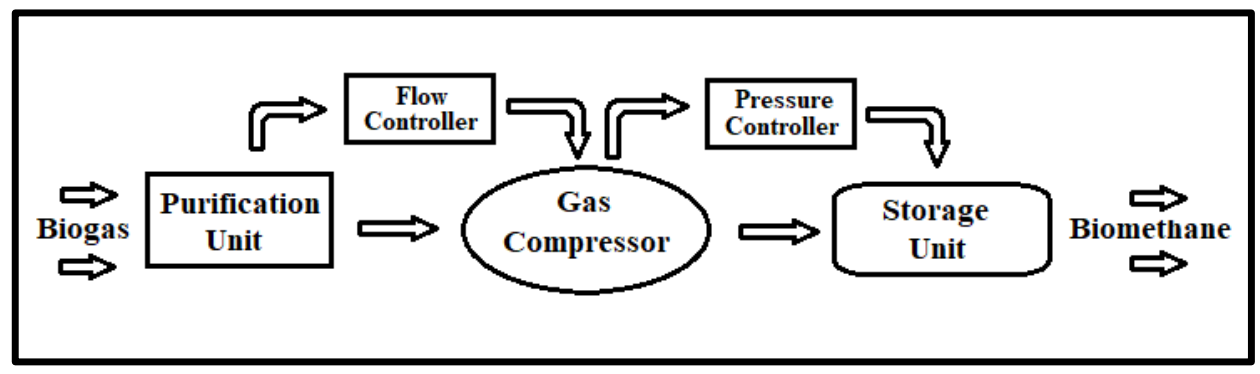

Fig. 2: A simplified block diagram of biogas treatment system. Working principle of gas treatment system

At startup, the electric motor starts rotating and also run the crankshaft attached to it hence, the piston starts motion inside the cylinder. During the piston moves downward, the raw biogas enters into the purification unit from the digester and then into the cylinder chamber of compressor by gas flowrate controller. And when piston moves upward, the compression of the biomethane starts and its pressure begins to increase. When the pressure increases up to its specific limit it pushes the discharge valve to open by pressure controller and the compressed gas is delivered to the storage unit. The obtained Biomethane is used in combined heat and power (CHP) applications to generate electricity and heat for its use in several applications. Biomethane may be storage for later use when usages require variable power or when production process is greater than energy consumption.

\section{Design considerations}

Design of the compressed biomethane system demand certain factors requirement to be specified before operation depending on the working and application. Knowledge of the pressure, actual capacity, theoretical capacity, volumetric efficiency, heating value and energy generation will enable the proper treatment system to be designed.

The performance of the developed system was experimentally measured under four different discharge pressures $(200,400,500$ and $600 \mathrm{kPa})$ and gas flow rates of $\left(2.0,2.4,2.8\right.$ and $\left.3.0 \mathrm{~m}^{3} \cdot \mathrm{h}^{-1}\right)$. 


\section{Compression ratio}

Suction pressure is the pressure at the compression system inlet expressed as $\mathrm{Ps}=1.013 \mathrm{bar}=101.3 \mathrm{kPa}$. While discharge pressure is the pressure generated on the high side of a gas compressor in a processing system expressed as $\mathrm{Pd}$. Compression Ratio, CR can be calculated by using the following equation:

\section{Compressibility factor}

$$
\mathrm{CR}=\frac{\mathrm{Pd}}{\mathrm{Ps}}
$$

The compressibility factor, CF becomes more significant for modifying the ideal gas status and estimation the real gas behavior. It is obtained from the state equation as follows.

$$
\mathrm{CF}=\frac{\mathrm{P}_{\mathrm{d}}}{\rho \mathrm{R}_{\text {spe }} \mathrm{T}_{\mathrm{d}}}
$$

Where: $P_{d}$ is the discharge pressure, $\rho$ is density of the gas $=0.657 \mathrm{~kg} \cdot \mathrm{m}^{-3}$ and $\mathrm{R}_{\text {spe }}$ is specific gas constant $=32.313 \mathrm{~kJ}^{\circ} \mathrm{C}^{-1}$ and the $\mathrm{T}_{\mathrm{d}}$ is the discharge temperature $=23,28,29$ and $30^{\circ} \mathrm{C}$.

\section{Actual capacity}

Relating to the actual capacity is usually obtained by the following equation:

$$
Q_{\text {act }}=\frac{\mathrm{Vg}}{t}
$$

Where: $\mathrm{Vg}$ is volume of obtained methane sample and $\mathrm{t}$ is the time consumed in the treatment operation.

\section{Theoretical capacity}

Theoretical capacity can be calculated by using the following equation.

$$
Q_{t h}=\frac{C F R T_{s} \dot{M}}{P_{S}}
$$

Where: $\mathrm{R}$ is gas constant $=0.5183 \mathrm{~kJ} \cdot \mathrm{kg}^{-1} \cdot{ }^{\circ} \mathrm{K}^{-1}$ and $\dot{M}$ is mass flow rate.

\section{Volumetric efficiency}

The following equation may be used to determine volumetric efficiency.

$$
\eta_{\mathrm{v}}=\frac{Q_{a c t}}{Q_{t h}}
$$

\section{Power consumption of treatment system}

Energy consumption is determined from the maximum shaft power with margin of $10 \%$ over maximum power and 5\% tolerance. It is specified by considering all components and factors which required power as input. 


$$
P=\frac{P_{s} Q_{t h}}{\eta_{v}}\left[\frac{n}{n-1}\right]\left[C R^{\left(\frac{\mathrm{n}-1}{\mathrm{n}}\right)}-1\right]
$$

Where: $\mathrm{P}$ is required power for operating gas compressor. The electric motor for the treatment system, which was selected based on the load characteristics of the system. The power of the electric motor is $0.5 \mathrm{~kW}$ obtained using a service factor of 1.5 assumed to operate continuously.

\section{Heating value}

Heating value is a magnitude of a fuel's energy density and is expressed in energy unit per specified amount. heating value, HV can be calculated using the following equation.

$$
\mathrm{HV}=\%_{\mathrm{CH}_{4}} \times \rho \times \mathrm{LHV}
$$

Where: $\% \mathrm{CH} 4$ is the percentage of methane obtained after purification process

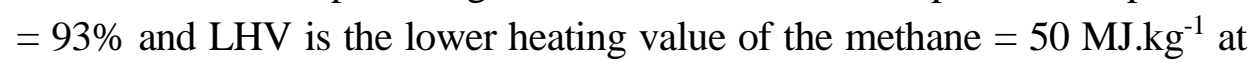
standard conditions. The equations have been used in this study according to (Cengel and Boles 2015) and (Chaitanya et al., 2017).

\section{Energy Generation}

Energy Generation can be calculated using the following equation.

$$
\mathrm{EG}=\frac{H V}{3.6}
$$

Where: EG is energy generation and HV is heating value.

\section{RESULTS AND DISCUSSION}

This study presents technology of integrated biogas treatment system in the form of a combined experimental scale to provide a new opportunity for development and progress of biogas plan. The results of this research will be discussed under the following items:

\section{Actual capacity and volumetric efficiency}

Representative values of both actual capacity and volumetric efficiency of biomethane compression unit versus pressure are given in Figs 3 and 4. It was noticed that increasing the discharge pressure from 2 to 6 bar increased the actual capacity from 0.73 to 1.55 , from 0.89 to 1.88 , from 1.04 to 2.20 and from 1.12 to $2.36 \mathrm{~m}^{3} . \mathrm{h}^{-1}$, respectively.

On the other hand, results show that increasing gas flow rate increased volumetric efficiency under different discharge pressure levels. It was noticed that the highest volumetric efficiency values were $91.25,91.75$, 92.04 and $92.56 \%$ measured at gas flow rates of 2.0, 2.4, 2.8 and $3.0 \mathrm{~m}^{3} \cdot \mathrm{h}^{-}$ 
${ }^{1}$ respectively at discharge pressure of 2 bar. While the lowest values were $83.78,84.30,84.62$ and $84.89 \%$ at discharge pressure of 6 bar and the under same pervious flow rates, respectively.

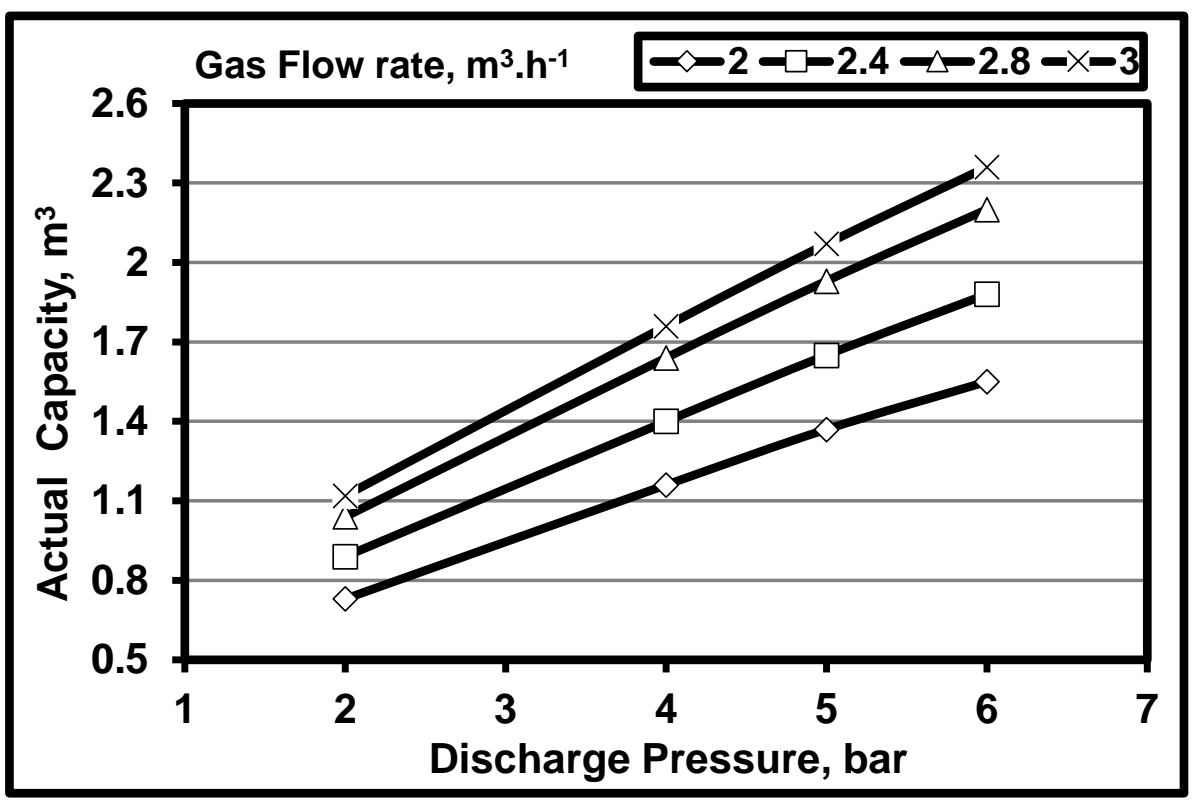

Fig. 3: Effect of discharge pressure on the actual capacity.

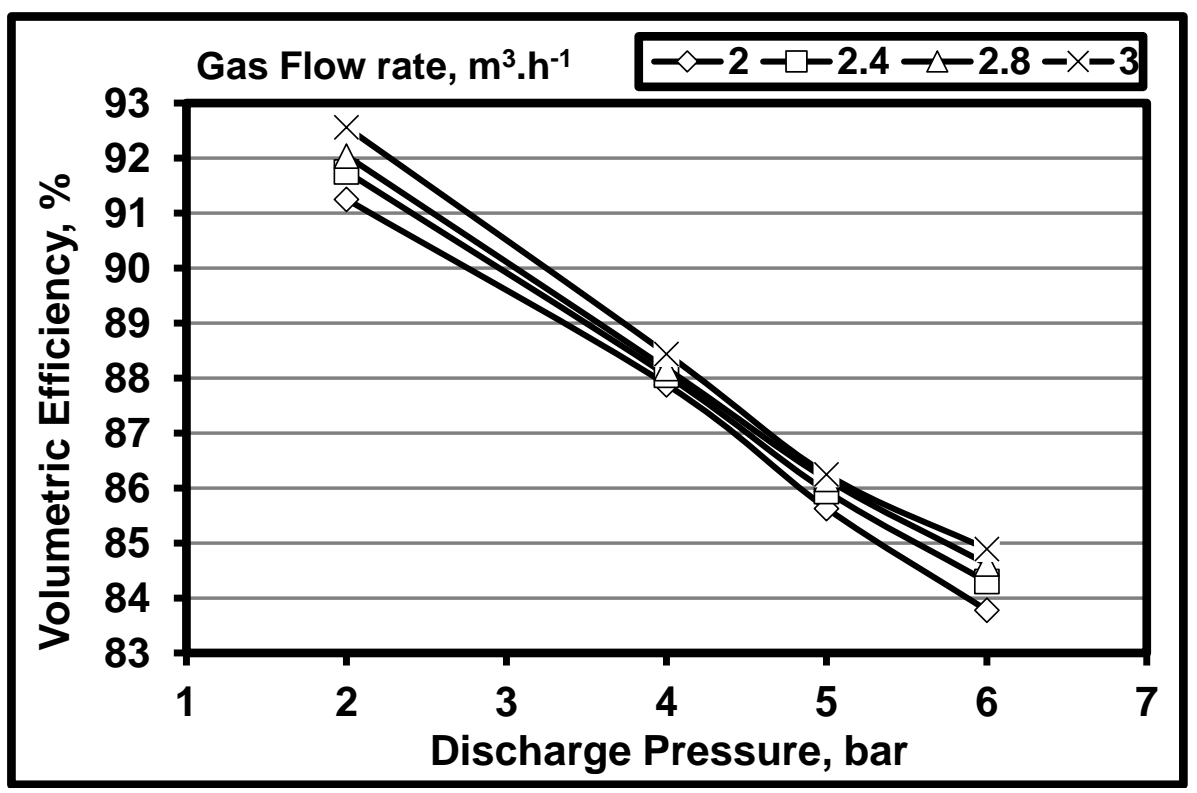

Fig. 4: Effect of discharge pressure on the volumetric efficiency. 
The biomethane capacity values increased by increasing the discharge pressure as a result of both increase the compression factor and gas flow rate at the same time unit for compressed methane gas. Also, the volumetric efficiency increased by increasing flow rates because of the increase of actual capacity that lead to raise methane flow through the drainage outlet at the same unit of time.

\section{Energy Consumption}

Discharge pressure has an obvious effect on energy consumption, these graphical relationships can be remarked in Fig. 5 under different gas flow rates of $2.0,2.4,2.8$ and $3.0 \mathrm{~m}^{3} \cdot \mathrm{h}^{-1}$.

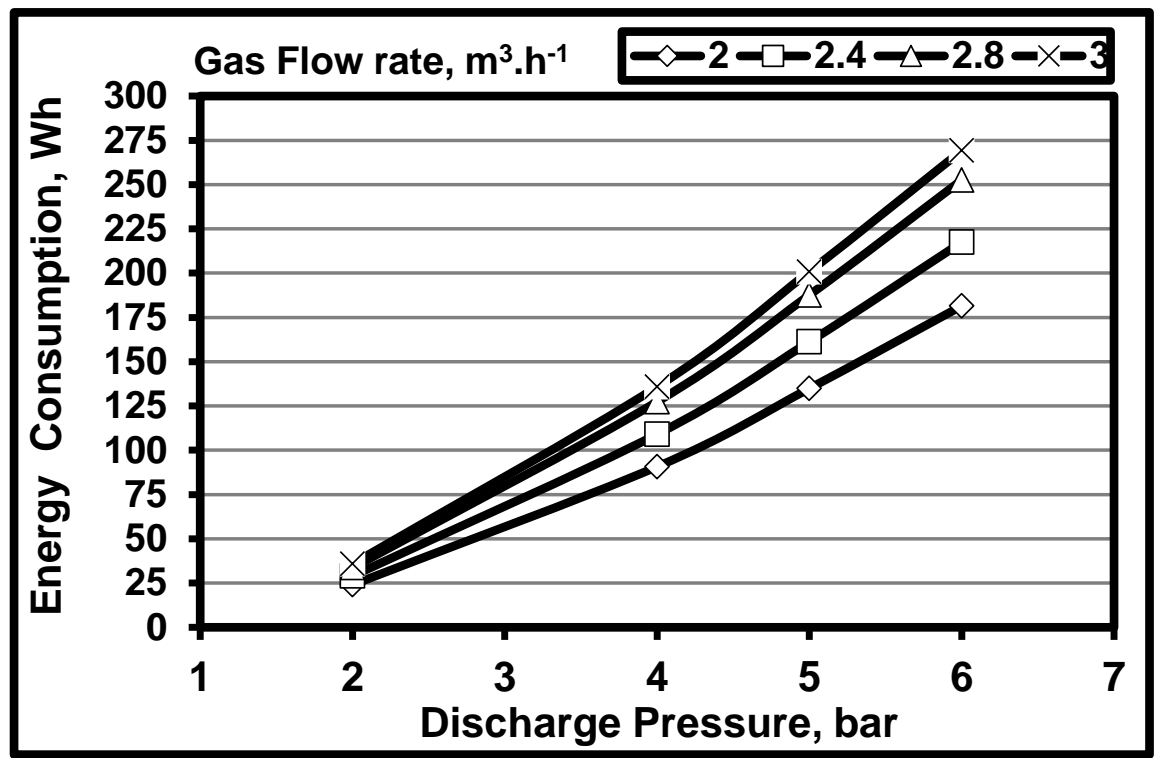

Fig. 5: Effect of discharge pressure on energy consumption.

It was evident that the lowest energy consumption values were 24.02, 28.96, 33.63 and 35.81W.h at discharge pressure of 2 bar. While the highest values reached 181.50, 217.43, 252.55 and $269.18 \mathrm{~W}$.h at pressure of 6 bar. The energy consumption was attributed to compression ratio and throughput capacity affecting the treatment system devices which consumed less energy compared to the energy generated.

\section{Energy Generation}

This measurement is one of the most important indicators that highlight the role of this study to meet the country's fuel requirements as well to provide a new perspective for sustainable and renewable energy development. Values 
of both the heating value and the energy generated from the integrated biogas treatment system were estimated versus the actual capacity as shown in Figs. 6 and 7 under gas flow rates of 2.0, 2.4, 2.8 and $3.0 \mathrm{~m}^{3} \cdot \mathrm{h}^{-1}$.

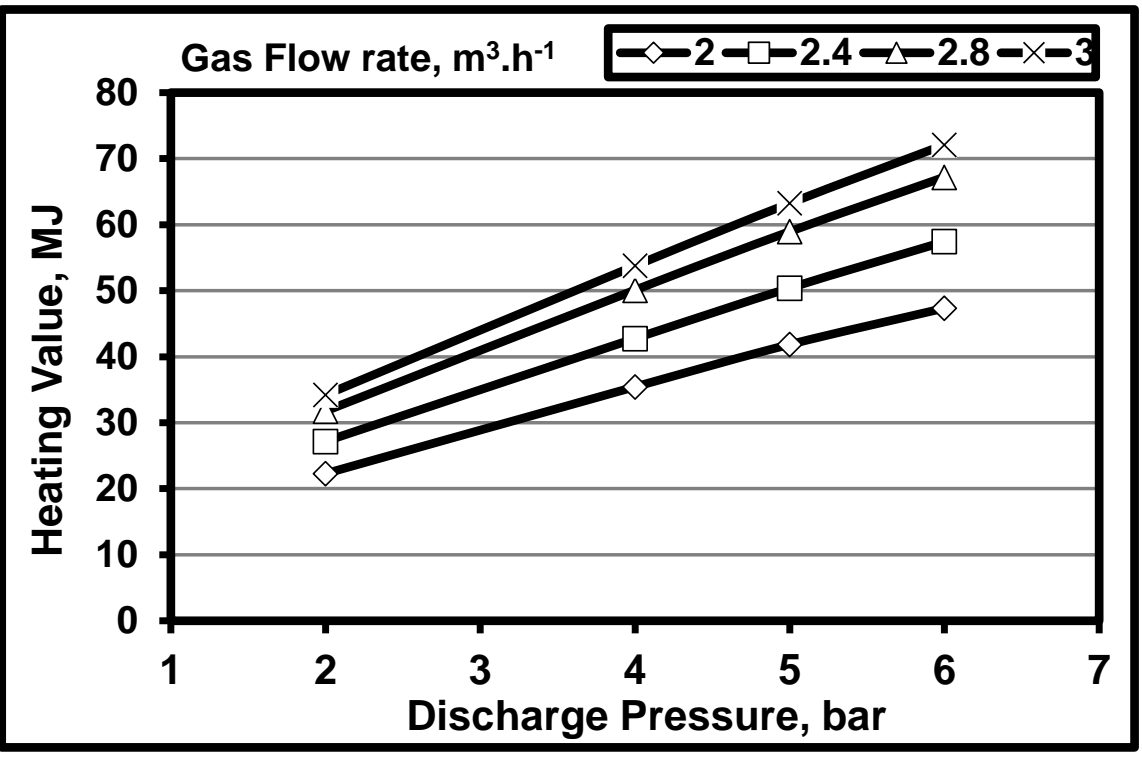

Fig. 6: Effect of discharge pressure on heating value.

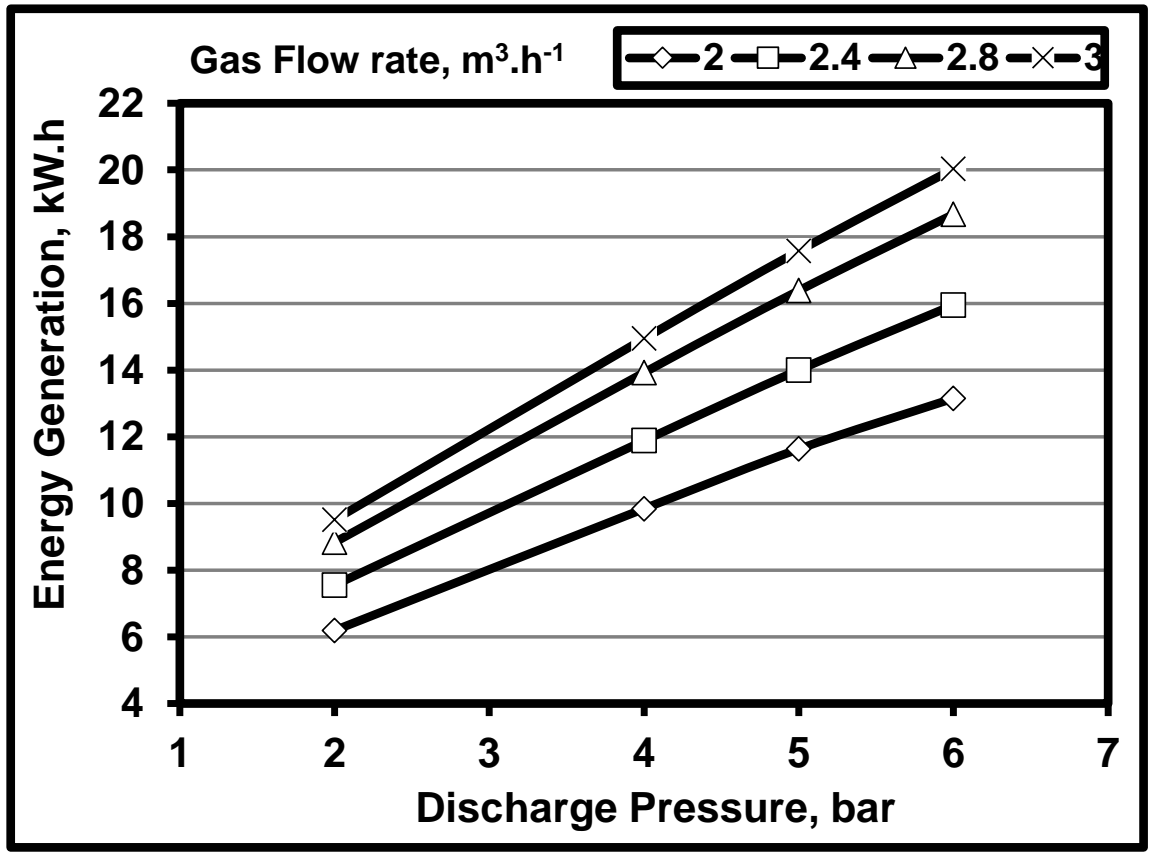

Fig. 7: Effect of discharge pressure on energy generation. 
It was observed that increasing the discharge pressure from 2 to 6 bar increased the heating value from 22.30 to 47.35 , from 27.19 to 57.43 , from 31.77 to 67.21 and from 34.22 to 72.10 MJ.h. Concerning energy generated from the treatment system, it was noticed that the highest values of energy generation were $13.15,15.95,18.67,20.03 \mathrm{kWh}$ at discharge pressure of 6 bar. While It should be noted that the lowest values were 6.19, 7.55, 8.83 and $9.51 \mathrm{kWh}$ at pressure of $2 \mathrm{bar}$ and under the same pervious of flow rates. Higher values of both the heating value and the energy generated were associated with the percentage of methane obtained after purification process as well as the biomethane productivity during compression process.

\section{CONCLUSION}

Compressed biomethane gas (CBG) is the fuel of most appropriate choice and necessary for Egypt and the world. Biogas can be cleaned, purified and compressed to meet the country's fuel requirements and therefore provide a new opportunity for development and progress of biogas plan in the country. On the studies achieved, it is clearly visible that the renewable energy and other alternative energy sources need to be exploited on the background of conventional fuels and climate change matter. Biomethane gas is visible to be one of the best alternate as depicted in this work. It is demonstrated that compressed biomethane could store successfully in the bottling cylinder after purification process under discharge pressure of 6 bar and gas flow rate of 3 $\mathrm{m}^{3} \cdot \mathrm{h}^{-1}$ which achieves the highest value of theoretical capacity, actual capacity, actual heating value and energy generation. Therefore, it is clear that purification, compression and bottling of biomethane using an integrated biogas treatment system will ease onus about conventional sources as an energy source with efficiency improvement. The commercial application of proposed system could lead to improved use of renewable energy technology and could minimize the foreign exchange cost pressure.

\section{REFERRENCES}

Budzianowski, W. M., C. E. Wylock and P. A. Marciniak (2017): Power requirements of biogas upgrading by water scrubbing and biomethane compression: Comparative analysis of various plant configurations. Energy Conversion and Management, 141(1): 2-19. 
Cengel, Y. A. and M. A. Boles (2015): Thermodynamics: An Engineering Approach. McGraw-Hill Education, 8th Edition.

Chaitanya, D. P., M. R. Khodke and A. Baheti (2017): Design calculations to evaluate performance parameters of compressor valve. International Journal of Advance Engineering and Research Development (IJAERD) 4(7): 602:608.

Gaikwad, V. R. and P. K. Katti (2015): Biogas compression and bottling: a solution to energy crises. International Journal of Computer Applications, NCRENB-15, 13:16.

Mohanty M. K., N. H. Ray and R. C. Mohanty (2016): Biogas Compression and Storage System for Cooking Applications in Rural Households. International journal of renewable energy research, Vol.6(2): 593:598.

Nallamothu R. B., A. Teferra and B. A. Rao (2013): Biogas purification, compression and bottling. Global Journal of Engineering, Design \& Technology, 2(6):34-38.

Ryckebosch, E., M. Drouillon and H. Vervaeren (2011): Techniques for transformation of biogas to biomethane, Biomass and Bioenergy, 35: 1633-1645.

Yadav, S. P., N. A. Sutar and N. Vinayaka (2018): Study of biogas bottling process and modification work in cascade. International Journal of Mechanical Engineering and Technology, 9(6):202-209.

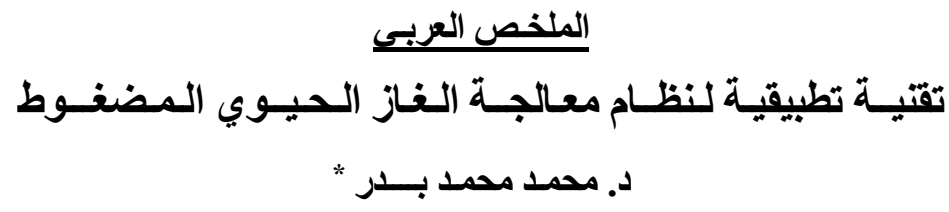

فى ظل الطلب المتز ايد على الطاقة في الآونة الأخيرة نتيجة التطور الصناعي والاقتصادي الذي أدى الذى

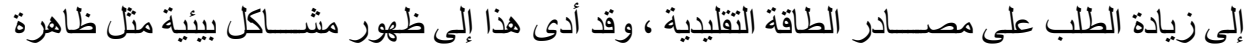

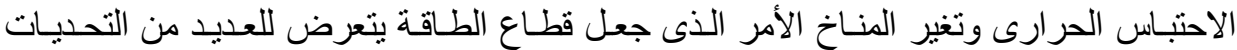

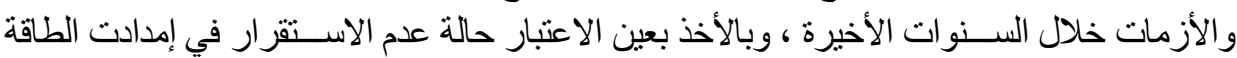

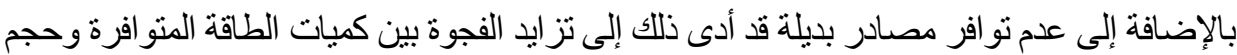
الطلب عليها.

* قسم الهندسة الزراعية - كلية الزراعة - جامعة الزقازيق - مصر. 
هذه التحديات قد أثرت بشكل سلبى على العديد من القطاعات الحيوية فى كثير من دول العالم و لا سيما

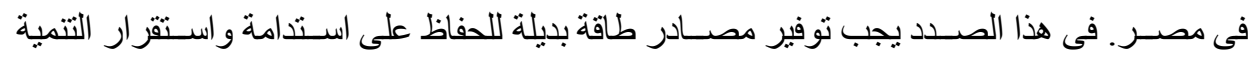
الصـــناعية المســـمرة للنهوض بكافة القطاعات ســـو اء الحكومية أو الخاصـــة وذللك لتحقيق التتمية

المستدامة.

يعتبر الميثان الحيوي أحد أهم المصسادر البديلة التى يمكن الاعتماد عليها كوقود صسيق للبيئة ، نظيف

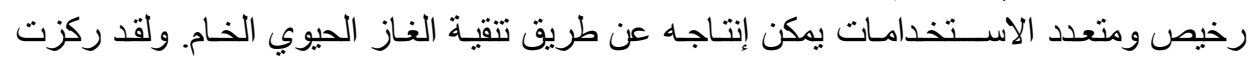
الدر اسات السابقة بعملية إنتاج الغاز الحيوي من جو انب متعددة دون العمل على تصميم نظام تطبيقيى

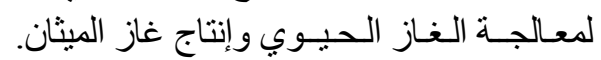

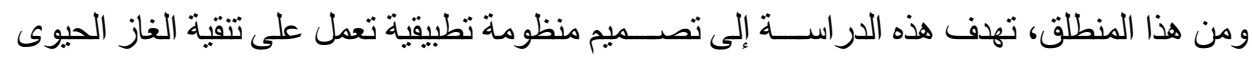

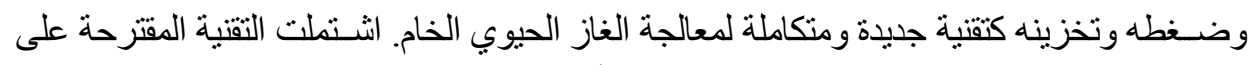

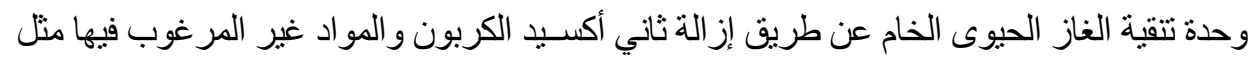

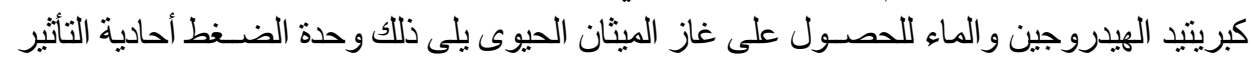
لضغط وتعبئة غاز الميثان بالقيمة المطلوبة لكل من الضغط ومعدل التصرف فأ باستخدام متحكم الضغط الضئ

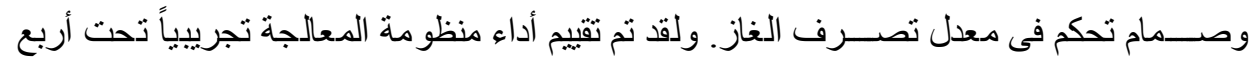

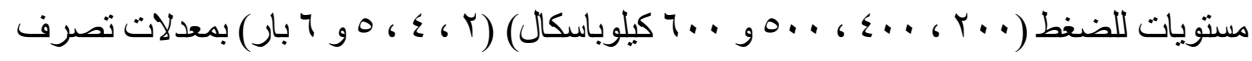

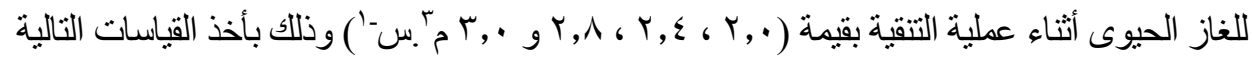

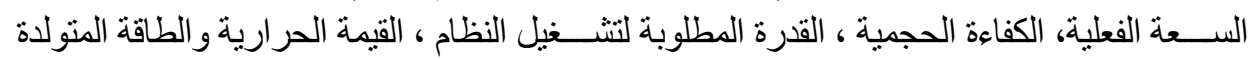
لتقييم المنظومة المقترحة بشكل أكثر شمولية.

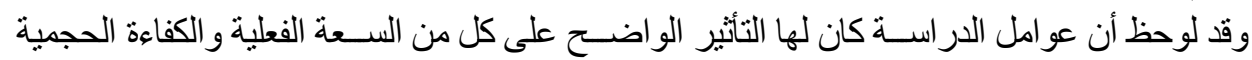

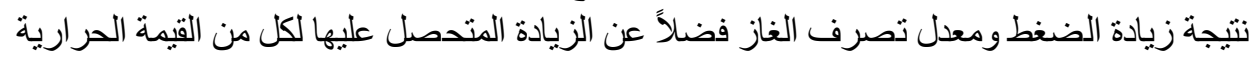

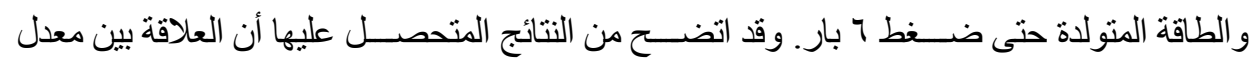
تصـرف الغاز وضـغط التخزين كانت علاقة طردية ومن ثم يمكن تحسين عملية استخلال طاقة غاز

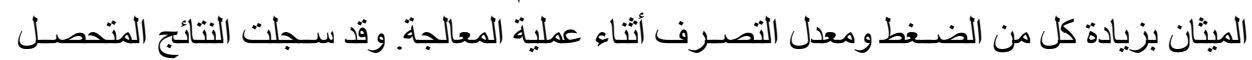

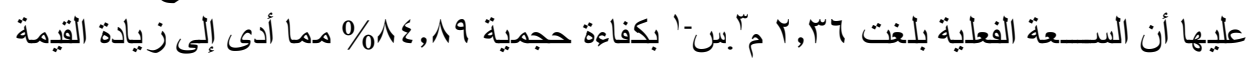

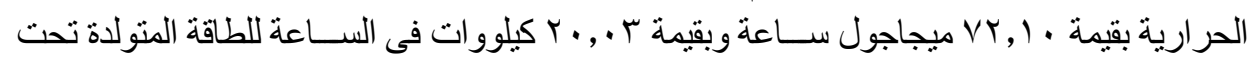

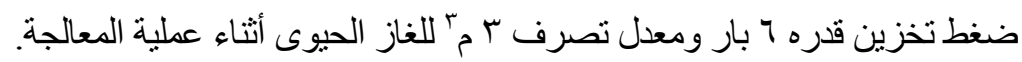

